\title{
THE EMBRYOLOGY OF A COMMON FLY.*
}

Since 1886 five investigators, Kowalevsky, Blochmann, Bütschli, Henking, and Voeltzkow have contributed important observations on portions of the embryology of common muscids (Calliphora, Lucilia). To this list Prof. Graber's work is now to be added as the most comprehensive and voluminous. This paper is worthy of special attention, coming as it does from an eminent entomologist who has for years been actively productive in a field which many a younger investigator has deserted after contributing a short memoir on some common insect.

Prof. Graber's treatise covers nearly the whole ground of embryonic development in Musca beginning with the cleavage of the egg and concluding with a description of the nervous system and the formation of the imaginal discs. To our knowledge of the preblastodermic stages he cannot be said to have added any really important facts, although he has succeeded in correcting some of Voeltzkow's errors.

The formation and evolution of the germlayers of Musca constitutes the all-important topic of the paper. After devoting a preliminary chapter to some observations on Aphis, in order to disprove Will's statement that the mid-gut arises from the yolk-cells (vitellophags), Prof. Graber attacks the subject in Lucilia and Calliphora, pointing out step by step as he proceeds the points wherein he agrees or disagrees with his predecessors. The main question: Do the vitellophags take part in the formation of the mid-gut? was answered negatively by Kowalevsky, Bütschli and Voeltzkow and to this conclusion Prof. Graber assents. In this important point he

*Vergleichende studien über die embryologie der insecten und insbesondere der musciden. Von Veit Graber. Denkschr. d. math. naturw, classe d. k. akad. d. wiss. Wien, bd. 56. I\$89. (4to. p. 257-314. 10 plates.) cannot be said to have made any great advance, his observations being merely corroborative of the results obtained by other recent investigators besides those who have worked on Musca. The fatiguing length to which Prof. Graber goes in describing his sections would be unpardonable, were it not that he had not read Heider's work on Hydrophilus or his present critic's paper on Doryphora before publishing.

To the important subject of the relations of the fore- and hind-gut to the blastopore Prof. Graber has contributed some interesting observations, although his remarks, as we hope to show presently, must be received with some reservations. His results are very briefly these: The fore-gut (stomodaeum) is formed near the anterior end of the gastrula raphe as a distinctly ectodermic invagination whereas, on the other hand, the hind-gut (proctodaeum) appears to be formed as a deepening of the gastrular groove at the posterior end of the embryo. Its walls are consequently of mesentodermic origin. Besides the elongate median gastrula, familiar to all students of insect embryology, Prof. Graber describes two pairs of grooves which run parallel with the median groove and also contribute in the formation of the mesentodermic layer. These grooves thus constitute a lateral gastrulation. Their relations to one another and to the median groove are not easily understood from the description and Prof. Graber should have introduced diagrams to show their exact position and extent. The true morphological significance of the lateral gastrulation is not explained and as nothing comparable to it has been observed in other insects, the observation has as yet only the value of an interesting and isolated fact. The author's suggestion that the small grooves may be a new formation introduced for the purpose of augmenting the mesentoderm is, to say the least, improbable, when 
we take into consideration the great extent of the median invagination in Musca and the small size of the blastopore in certain Orthoptera where no lateral gastrulation has been observed.

One may venture to object to some of the new terms of which Prof. Graber has been rather prodigal in his latest papers. The time-honored term "blastoderm" is easily understood and it is difficult to see why it should be relegated to the biological attic for effete nomenclature to make room for an only remotely suggestive term like "cycloblast." Prof. Graber now dubs the yolk-cells "centroblasts" notwithstanding the termination "blast" is properly applied only to tissues of a germinal or formative character and not to elements which, like the yolk-cells, degenerate and take no part in building up the insect. It would be wiser to suspend the use of terms like "ptychoblast" till we possess a better knowledge of "arthropod" germ-layers, as we have still a great deal to learn on this subject. In the meantime "mesentoderm" is quite clear and will answer all purposes. "Entomyoderm" and "ectomyoderm" are scarcely to be regarded as improvements on the old terms, "splanchnopleure" and "somatopleure." We supposed that Prof. Graber's terminological fecundity was exhausted when he gave us the sesquipedalian, "ectoptygmatorhegmagenous ptychonotogony.' But these are small blemishes in a work which will rank among the more important contributions to insect embryology.

The chief value of Prof. Graber's paper cannot be said to lie in a furthering of what we must regard as one of the chief aims of the study of insect development, viz: a know edge of the mutual phylogenetic relations of the existing orders of insects (often separated by wide gaps, towards the bridging of which comparative anatomy and paleontology have contributed only a little), and a knowledge of the relations of insects, as a class, to other arthropod groups and to their remote ances. tors, the annelids. In our estimation Prof.
Graber's work is chiefly valuable as showing to what an extent the embryonic development of a calyptrate muscid has been deflected from the ancestral path - in other words, it is an admirable picture of one of the "short-cuts" in insect development.

It will be remembered that the egg of the fly hurries through its whole development in about 24 hours, that it is provided with a relatively small quantity of yolk, and that the characters of the secondarily developed and degraded maggot have been reflected back into embryonic life. That this reflection has materially altered the original ontogeny as displayed by older forms such as the Orthoptera and Hemiptera, is evident from the fact that the embryo no longer exhibits the typical cephalic and thoracic appendages, to say nothing of the abdominal appendages (embryos of bees, beetles with apod larvae and fleas still develop thoracic legs!). Moreover the ammion and serosa are rudimentary in Musca; the head has become pro. foundly and strangely modified and the mesodermic layer no longer exhibits the typical paired coelomic cavities. It is, therefore, obvious that conclusions drawn from the embryogeny of a muscid cannot without extreme caution be extended to cover other insects. It is further evident that to ascertain the exact path of development in an insect that develops so rapidly a very great number of eggs must be examined to insure certainty in regard to the different steps in the hurried sequence of tissue-changes. Granting the correctness of Prof. Graber's observation that the proctodaeum is of mes. entodermic origin, we may perhaps account for this condition on the supposition that whereas in other insects of slow development the hind gut is not formed till after the closuse of the posterior end of the blastopore, in Musca the processes of growth succeed one another so rapidly that the blastopore does not have time to close before the hindgut is found. Thus the apparently mesentodermic character of the hind gut would 
be a secondary condition due to acceleration of development.

The ro plates with 127 figures illustrating Prof. Graber's papers are beautifully executed and are by far the most accurate ever published on the subject. It is to be regretted that Prof. Graber did not introduce larger, clearer and more numerous diagrams. The need of these is especially urgent as it is next to impossible to obtain good surface views of the fly's egg, and mental reconstruction, even from such excellent sections as those given in the plates, is no easy task for the reader.

It is to be hoped that the next investigator who undertakes the study of the Musca egg will make use of the wax reconstruction methods now so succesfully employed by workers in other flelds of embryology.

W. M. Wheeler.

\section{OENEIS AND ITS EARLY STAGES.}

At the last (May) meeting of the Cambridge entomological club Mr. S. H. Scudder spoke of the group of Oeneides as one of the most interesting of butterfly genera, partly because (using the word in a restricted sense) there was no other genus of butterflies in which so many species were common to the Old and New Worlds, but more because it is the only genus entirely restricted to high latitudes and altitudes and widely spread in the world. Eight species occurred in Europe-Asia, of which two or three were also found in North America, which possessed besides at least eight or nine species. One would suppose that it would be one of the last with the early stages of whose life we should be acquainted, and this was the case until recently, but now more or less has been published concerning eight of the species, mostly from observations in this country, and it is understood that Mr. W. H. Edwards, to whom most of this advance is due, has full or tolerably complete histories of two or three more.

I had the good fortune, he remarked, to be the first to publish an account of the early stages of one of the species of the genus Oeneis semidea, the only one found in New England,- due to the joint efforts of the late Messis. Shurtleff and Sanborn and myself, though no one has yet carried the creature through from the egg. Since then most of the additions to our knowledge of American species have come from Edwards, but Fyles has published the history of Oe.jutta to which Fletcher and I have added something, and in Europe, where the same species occurs, Holmgren and Berg. One of the latest known species, Oe.macounii, is now almost completely known, thanks to $\mathrm{Mr}$. J. Fletcher, who has published an account of it, and the egg and first larval stage have also been described by Mr. W. Beutenmüller. All that is known of chryxus, iduna, and ivalda, is due entirely to the indefatigable efforts of $\mathrm{Mr}$. Edwards.

Of the European species also, it so chanced that $I$ was the first to publish anything (a year previous to Berg's account of Oe.jutia) describing the egg and first larval stage of Oe.aello, the alpine species, to which nothing has since been added; and excepting $O e$. jutta, before referred to, the early stages of only one other species, Oe.bore, are known, due to the studies of Sandberg.

Out of sixteen or seventeen species, then, recognized in the northern hemisphere, we now know more or less of the transformations of about half the species not to mention the two or three which Edwards has worked out but not yet published. This is a remarkable showing for a group of butterflies with such a distribution, and brings out several features which are a little puzzling. First, there are two types of surface sculpture in the eggs; the more common is that in 

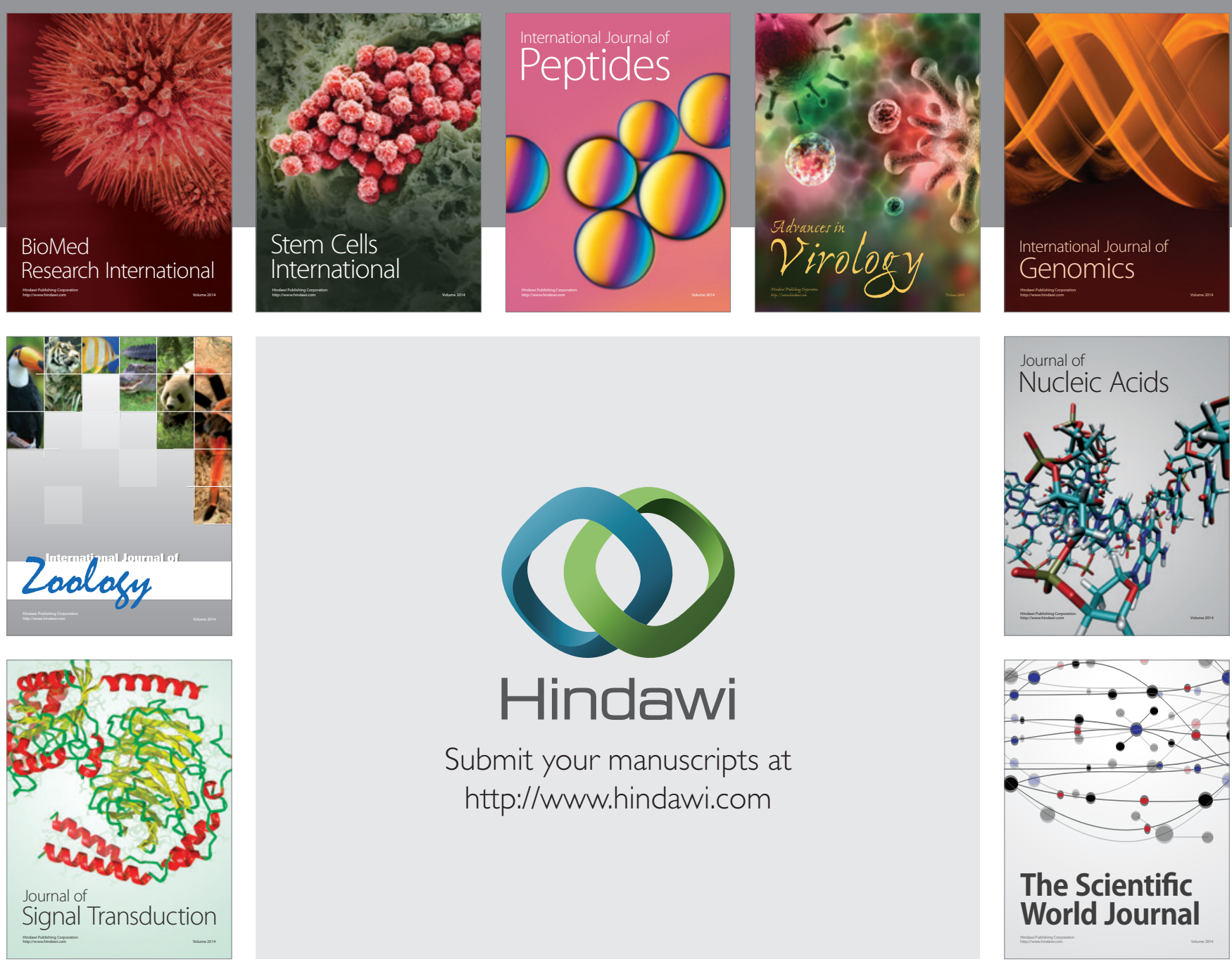

Submit your manuscripts at

http://www.hindawi.com
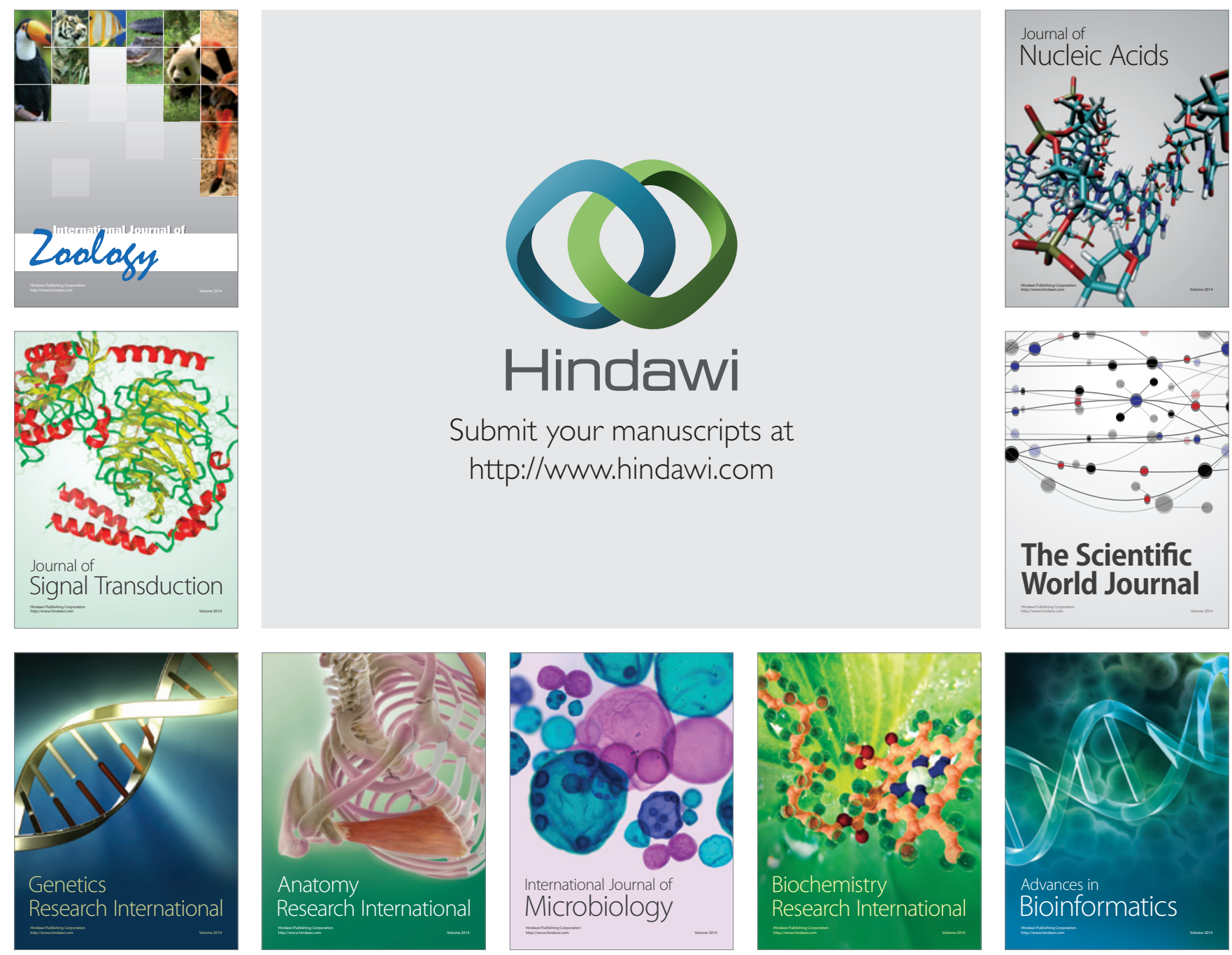

The Scientific World Journal
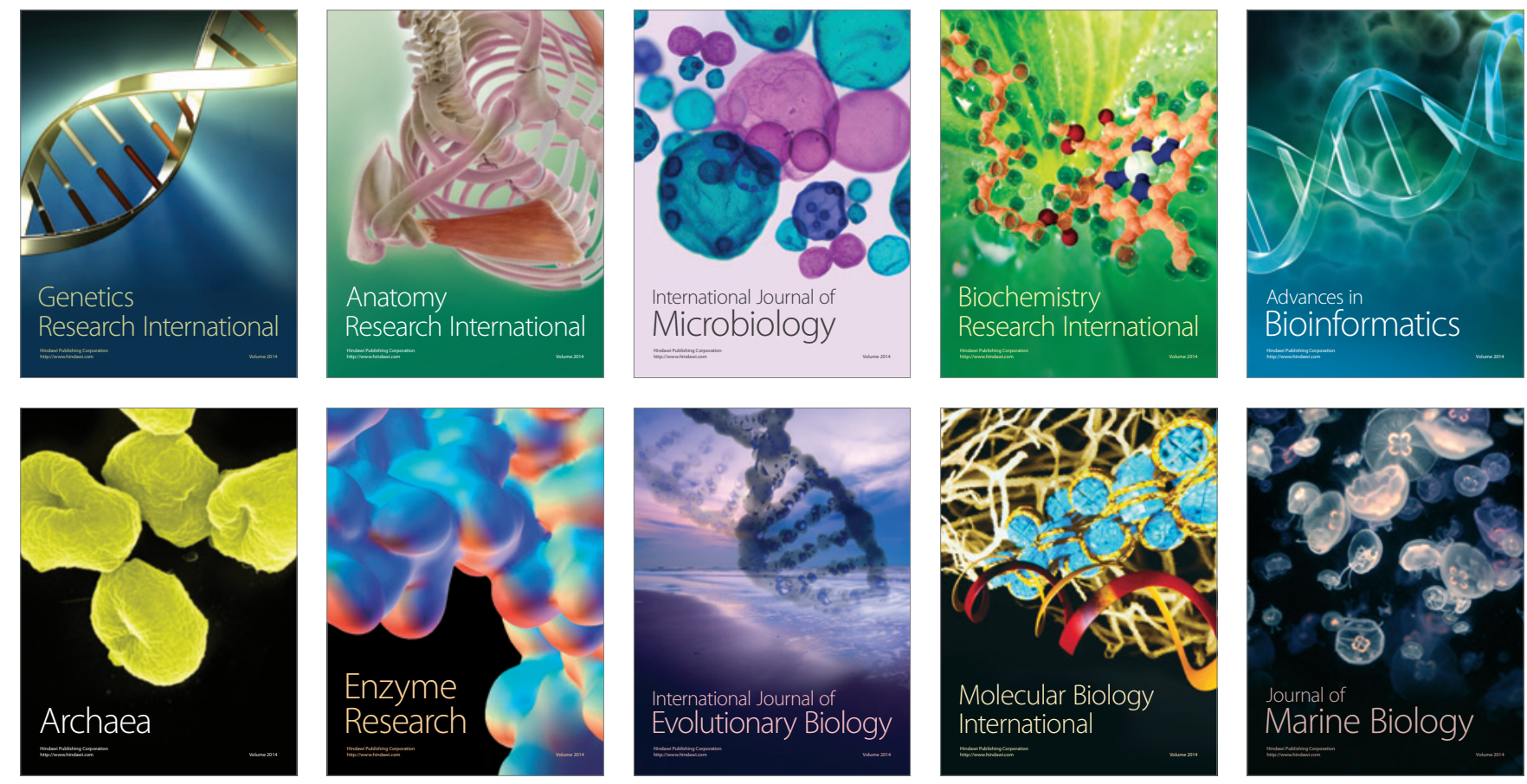